\title{
Las lenguas ístmicas: entre obsolescencia y resistencia ${ }^{1}$
}

\section{Miguel Ángel Quesada Pacheco ${ }^{2}$}

\author{
Universidad de Bergen, Noruega
}

\section{RESUMEN}

Se analiza la situación actual y perspectivas de estudio y protección de dos lenguas indígenas ístmicas, de la familia chibcha: el boruca y el guaymí. A su caracterización genealógica y estado de conservación, se añaden las experiencias realizadas a favor de su conservación: además, se formulan propuestas para estimular nuevos trabajos que fortalezcan ese patrimonio cultural y lingüístico regional.

\begin{abstract}
An analysis is conducted of the present situation and prospects for the study and protection of two Central American indigenous languages in the Chibcha family: Boruca and Guaymi. In addition to their genealogical characterization and their state of conservation, a description is provided of the efforts made to conserve them; proposals are also made to foment new research which could fortify this cultural and linguistic regional heritage.
\end{abstract}

Palabras clave: Lenguas indígenas, familia chibcha, el boruca, el guaymí, etnolingüística

Keywords: Indigenous languages, Chibcha family, Boruca, Guaymí, ethnolinguistics

\footnotetext{
1 Ponencia presentada en el marco del I Simposio del Programa Lenguas Indigenas de la Baja Centroamérica (PROLIBCA), llevado a cabo en setiembre de 2007, en la ciudad de Heredia en el Campus Omar Dengo de la Universidad Nacional de Costa Rica.

2 Correo electrónico: miguel.quesada@roman.uib.no
} 


\section{Introducción}

Esta comunicación tiene tres propósitos. En primer lugar, presentar, de manera general, la situación lingüística de dos pueblos indígenas de la Baja Centroamérica con raíces comunes, tanto en la dimensión lingüística como en la cultural, que por vicisitudes históricas se han visto obligados a seguir dos caminos totalmente distintos en la preservación de su patrimonio lingüístico y cultural. Me refiero en particular a dos lenguas ístmicas: el boruca (Costa Rica) y el guaymi (Panamá). En segundo lugar, sentar las bases para una discusión crítica sobre las políticas por seguir con miras a una colaboración, por parte de los investigadores científicos no indígenas, para salvaguardar el patrimonio lingüístico de los pueblos amerindios en agudo proceso de extinción. En tercer lugar, crear conciencia entre los investigadores, sobre la necesidad de aunar esfuerzos interdisciplinarios para estudiar y salvaguardar el patrimonio lingüístico y cultural de América Central, pues, tal como afirman López y Küper³:

Es menester recordar que cuando se extingue una lengua se muere no solo parte de la historia y del patrimonio de la humanidad, sino también y sobre todo un conjunto de saberes y conocimientos desarrollados, acumulados y transmitidos a través de los miles de años por seres humanos que aprendieron a convivir con la naturaleza y a sobrevivir en determinados ecosistemas que, en muchos casos, hoy son espacios estratégicos para la supervivencia de nuestra especie.

3 Luis Enrique López y Wolfgang Küper, «La educación intercultural bilingüe en América Latina: balance y perspectivas», Revista Iberoamericana de Educación 20 (1999): 17-85. 


\section{Datos generales de las comunidades boruca y guaymí}

El pueblo boruca tiene unos 2017 habitantes (un 7,4\% del total de indígenas de Costa Rica) repartidos principalmente en dos territorios indígenas, Boruca (1386 habitantes) y Yimba o Rey Curré (631 habitantes) ${ }^{4}$, ambos distantes unos diez kilómetros, al sur de la provincia de Puntarenas, hacia la frontera con Panamá. Los borucas están en serio proceso de extinción como pueblo y comunidad cultural, aunque mantienen ciertos rasgos que han sobrevivido gracias a su comercialización, como es la artesanía (confección de flechas, máscaras y tejidos).

Los guaymíes, unos 160.000 habitantes, constituyen el grupo indígena más numeroso de Panamá y de la familia chibcha, pues conforma el $60 \%$ de los indígenas de ese país. Están distribuidos en las provincias deBocas del Toro (distritos de Chiriquí Grande y Bocas del Toro), en la costa atlántica; en Veraguas (distritos de Santa Fe, Cañazas y Las Palmas) y Chiriquí (distritos de Tolé, Remedios, San Félix y San Lorenzo), en la costa pacífica ${ }^{5}$. Además, en la actualidad se hallan unos 2500 guaymíes viviendo en Costa Rica ${ }^{6}$, y han emigrado varios grupos al Valle Central en busca de trabajos temporales, principalmente en la cosecha del café. Por esta razón se están haciendo visibles en ciertas zonas rurales del país; incluso se ven algunas señoras con sus hijos pidiendo limosna en San José y otras ciudades del Valle Central, situación totalmente desconocida entre las demás comunidades indígenas del área.

Tanto los borucas como los guaymíes basan su medio de subsistencia en la agricultura tradicional (cultivo del maíz, tubérculos, frijoles, plátanos, recolección de frutos, etc.) y en la comercialización

4 Datos extraídos de Solano Salazar (s.f.), según el censo de población nacional de 2000. La población total de habitantes en los territorios indigenas borucas es de 3.936 personas, incluidos los no indigenas. Elizabeth Solano Salazar, (s.f.). La población indigena en Costa Rica según el censo 2000, <http://www.ccp.ucr.ac.cr/noticias/simposio/pdf/solano.pdf $>$.

$5 \quad$ Ver <http://www.language-museum.com/g/guaymi.htm>.

6 Solano Salazar. 
de estos productos en pequeña escala. A diferencia de los guaymíes, los borucas han podido montar una eficiente infraestructura comercial para la venta de sus productos artesanales.

\section{Breve caracterización genealógica y tipológica del boruca y del guaymí}

Genealógicamente, el boruca y el guaymí son lenguas pertenecientes a la estirpe chibchense, que se extiende desde Honduras hasta Venezuela. De acuerdo con Constenla ${ }^{7}$, tanto el boruca como el guaymí pertenecen a la superfamilia chibcha $\mathrm{A}$ de dicha estirpe. Tipológicamente, son lenguas del orden SOV, con un sistema posposicional, con el orden poseedor-poseído y con paradigmas verbales cuya temporalidad o aspectualidad, así como la modalidad, van marcadas mediante sufijos o por perífrasis. En cuanto a diferencias estructurales entre estas dos lenguas, el guaymí tiene visos de ser lengua ergativa, con un sistema de clasificadores numerales determinados por la forma del objeto — plano, redondo, liso, etc.— que determinan ${ }^{8}$. Respecto del boruca, tiene esta lengua una partícula (qui) que entre otras funciones hace las veces de artículo, más una partícula enfatizadora $(a b i)$, y una topicalizadora (ang). Estas partículas, en el orden de los pronombres, forman tres paradigmas pronominales, según el énfasis que se le quiera dar a la acción que realiza el sujeto: cotidianidad, especificidad y topicalidad, respectivamente. En lo pertinente al sistema verbal, el boruca tiene dos paradigmas sufijales que marcan la aseveración y la negación, mientras que el guaymí lo hace mediante un adverbio de negación independiente ( $\tilde{a} a k a$ ), puesto a la izquierda del núcleo verbal.

$7 \quad$ Adolfo Constenla Umaña, Las lenguas del Área Intermedia: introducción a su estudio areal (San José: Editorial Universidad de Costa Rica, 1991) 42-43.

8 J. Diego Quesada, The Chibchan Languages (Cartago: Editorial Tecnológica, 2007); y Miguel Ángel Quesada Pacheco, Hablemos boruca (San José: Ministerio de Educación Pública, 1995). 


\section{Estado de conservación del boruca y del guaymí}

Estimando la gradación clasificatoria de James J. Bauman ${ }^{9}$ para el estado de conservación de las lenguas indígenas de los Estados Unidos frente al inglés - a saber: florecimiento, resistencia, declinación, obsolescencia y extinción - se podría observar la situación social del boruca y del guaymí en relación con la lengua española, conforme a los siguientes indicios ${ }^{10}$ :

A. La proporción de hablantes según sus edades y el grado de bilingüismo en boruca es prácticamente nula, pues casi todos son hoy en día monolingües en español; en guaymí, al contrario, casi todos son bilingües, pero además hay monolingües en este idioma.

B. En boruca no existe relación entre el número de hablantes borucas y los cambios que se dan en la población de la comunidad; por su parte, el guaymí está vivo y activo ante los retos de la sociedad moderna. Así, al contrario de los guaymíes, los borucas tienen una infraestructura mucho más acorde con las necesidades de la sociedad actual: cuentan con agua potable, electricidad, recursos informáticos, medios de difusión (sobre todo radio y televisión, naturalmente toda en español) y caminos vecinales transitables prácticamente todo el año, de manera que el contacto con el mundo exterior se da a cada rato y en cualquier momento que el habitante lo considere oportuno. A los guaymíes les llega una estación de radio en su idioma, con fines proselitistas religiosos.

9 James J. Bauman, A Guide to Issues in Indian Language Retention (Washington: Center for Applied Linguistics, 1980).

10 Tomados de Enrique Margery Peña, «Estados de conservación de las lenguas indígenas de Costa Rica frente al español», Seminario sobre Identidad cultural y modernidad. Nuevos modelos de relaciones culturales [Barcelona, 27-30 de noviembre de 1990] (1990): 1-7: y de Michael Prosse, «Apuntes sobre la puesta en práctica de políticas lingüísticas bilingües-biculturales en las lenguas indígenas en 4 países de América Latina», Estudios de Lengua y Cultura Amerindias. Universitat de Valencia (1994): 167-178. 
C. No hay fluidez del boruca entre los hablantes jóvenes, aunque sí entre los guaymíes.

D. Los pocos que hablan boruca han relegado ese idioma al ámbito familiar y circunstancial, mientras que los guaymíes organizan sus reuniones comunales en su lengua ancestral, y lo hablan sin empacho cuando están entre hispanohablantes.

E. En cuanto al grado de asimilación del boruca y del guaymí a las estructuras de la lengua dominante, ambos idiomas están en un mismo nivel. Fundamento la afirmación anterior en los textos recopilados en ambas lenguas, en los cuales se muestra la lengua boruca bastante bien conservada, considerando su grave peligro de extinción. Al igual que el guaymí, el boruca presenta ciertas palabras castellanas referentes a objetos culturales desconocidos y a algunos nexos (porque, cuando, entonces, etc.).

F. En relación con el grado de flexibilidad de estas lenguas para adaptarse a la cultura cambiante de la comunidad, ambas reúnen los mismos requisitos, con la diferencia de que los borucas, al contrario de los guaymíes, han preferido el camino más fácil, olvidar por completo su idioma.

G. Respecto del grado de alfabetización en estas lenguas y del derecho a una educación bilingüe, los borucas tienen enseñanza obligatoria y gratuita en la escuela primaria; que se sepa, los guaymíes panameños carecen de ella ${ }^{11}$.

H. En lo pertinente a la oficialización de la lengua a nivel local o nacional y su reconocimiento como parte del patrimonio cultural de la nación donde se habla, ambas lenguas, el boruca y el guaymí, gozan del mismo derecho.

De los parámetros anteriores se infiere que el boruca es el idioma más expuesto al olvido; el guaymí cuenta aún con potentes armas para

11 Por lo menos en las comunidades que visité en Chiriquí. Precisamente de esto se quejaban algunos dirigentes durante mi visita, pues el maestro de su localidad solamente se expresa en lengua española y no manifiesta ningún interés por cultivar ni promover el guaymí entre los alumnos. 
defenderse del predominio español y de la cultura mercantilista moderna. En lo que sigue se establecerán las razones históricas que han incidido en este resultado, y las medidas adoptadas por tales etnias para salvaguardar su patrimonio lingüístico.

\section{La experiencia boruca}

La etnia boruca se componía de escasos habitantes ya desde el siglo XVI. Según el censo del conquistador español Perafán de Ribera, había únicamente 350 borucas en $1569^{12}$. Las referencias sobre la cultura boruca durante la Colonia son mínimas; sobre la lengua, nulas: ni siquiera se recopila este idioma en el famoso Catálogo de las lenguas del mundo, realizado por encargo de Catalina II de Rusia, en $1789^{13}$. Debido a una fuerte asimilación forzada por parte de las autoridades coloniales, tanto religiosas como administrativas, en buena medida a causa de su situación geográfica estratégica ${ }^{14}$, los borucas fueron perdiendo su idioma ${ }^{15}$, de manera que, a finales del siglo XIX, el antropólogo estadounidense William Gabb notó su acelerado proceso de extinción con las siguientes palabras:

12 León Fernández, Indios, reducciones y el cacao (San José: Editorial Costa Rica, 1976) 26-30.

13 Véanse las lenguas costarricenses recopiladas en el siglo xvIII para este catálogo en L. Fernández, Lenguas indígenas de Centro América en el siglo xvIII (San José: Tipografía Nacional, 1892).

14 Estaban situados justo por donde pasaba el célebre Camino de Mulas de la época colonial, con lo cual hubo un interés palpable de las autoridades coloniales por conquistar los indígenas del Pacífico sur. Boruca fue el centro misionero de los franciscanos en esta región del país y paso obligatorio de descanso en el viaje hacia Panamá; además, tenía gran importancia económica debido a la explitación de sus tejidos e hilados, teñidos con tinta múrex (cfr. Solórzano, 62-64). Juan Carlos Solórzano, «Evangelización franciscana y resistencia indígena: dos rebeliones en la frontera entre Costa Rica y Panamá». Anuario de Estudios Centroamericanos (Universidad de Costa Rica) 28(1-2) (2002): 57-88.

15 Según Solórzano (p. 97), los borucas «empleaban la lengua española y habían adoptado elementos culturales del mundo hispánico. Sin embargo, su alejamiento del Valle Central les permitió mantener su identidad cultural hasta bien entrado el siglo xx». Juan Carlos Solórzano, «Indígenas y neohispanos en las áreas fronterizas de Costa Rica (1800-1860)». Anuario de Estudios Centroamericanos 25 (2) (1999): 73-102. 
Los borucas van adquiriendo rápidamente el castellano, a expensas de las palabras correspondientes de su propio idioma. En un grupo de cinco borucas no hubo uno sólo que pudiera contar sino en castellano ${ }^{16}$.

A mediados del siglo xx persistían unos 15 hablantes monolingües en lengua boruca, y más de medio centenar de bilingües ${ }^{17}$. A partir de esta época el boruca entra en peligro de extinción. Para evitar esta pérdida, a partir de 1970 el maestro boruca Espíritu Santo Maroto, por iniciativa y esfuerzo personales, se preocupó por enseñar su lengua materna a los jóvenes. Por esa época se expresa de la siguiente forma:

los indios jóvenes y los niños han olvidado nuestra lengua o dialecto Brúncajc, a la que miran hasta con vergüenza. Ya es o era una raza vencida y humillada por arbitrariedades vergonzosas. En Boruca solamente el que escribe estas frases, y dos señoras ancianas más, hablan su antigua lengua. Creo o creemos que si no se sigue practicando las clases en lengua Brúncajc, como se está marchando, ayudado por la Junta Directiva «Conai», y comisiones indígenas, quedaría únicamente como recuerdo de la historia.

Por lo tanto: con empeños tan interesantes por este que escribe, con la Señora Primera Dama de la [República de] C.R., quien muestra su voluntad en favor de los Yndios de Boruca, para que definitivamente no desaparezca nuestra [sic] Idioma Bruncajc, con semejantes sacrificios, editaremos silabarios u otro libro

\footnotetext{
$\overline{16}$ William Gabb, «Tribus y lenguas indígenas de Costa Rica», León Fernández (ed.), Colección de documentos para la historia de Costa Rica (1875/1886). Tomo II (1870): 303-486 (404-405).

17 De acuerdo con datos suministrados en conversación personal con Nemesio González, semi hablante de la comunidad, son estas las últimas personas que él recuerda eran monolingües en lengua boruca, para 1950: Lupe Rojas, Onoria Morales, Concepción Rojas, Felipa Morales, Espirata Fernández, Mamita Díaz, Guadalupe Morales, Is Drubát R., Nazaria Morales, Gorgonia Morales, Espíritu Delgado. Faquina Lázaro, Viviana Lázaro, Justina Maroto y Paulina Portilla. Por esa fecha había, según sus cálculos, unas 62 personas bilingües en boruca y español.
} 
para que los indios escolares aprendan a escribir como hablan pues esta será una medida muy conveniente ${ }^{18}$.

Desconozco si las entidades mencionadas por Maroto le dieron el apoyo solicitado, pero sus esfuerzos se hicieron efectivos con la redacción de diversos silabarios, un glosario y la traducción al boruca de numerosos escritos periodísticos, pero no logró publicarlos en vida $^{19}$. Su trabajo vio resultados concretos en la década de 1990 , cuando el Ministerio de Educación Pública y la Universidad de Costa Rica se unieron en la tarea de alfabetización escolar en lengua boruca $^{20}$. Además, muchos adultos que saben algo de boruca deben sus conocimientos a las clases de Maroto.

Hoy en día, desafortunadamente, los borucas continúan con indiferencia frente al porvenir de su lengua ancestral; lo único que queda para los investigadores es continuar con la tarea de recopilación, al estilo boasiano, por lo menos para salvaguardar del olvido lo que aún queda vivo. Al menos los borucas cuentan en la actualidad con numerosos materiales escritos y publicados (leyendas, cuentos, tradiciones, diccionarios), de manera que no todo está perdido; además, adoptaron la iniciativa de imponer el boruca como asignatura obligatoria en la escuela primaria, gracias a los notables esfuerzos de Carmen Rojas $^{21}$, quien ha recopilado quizás el más valioso tesoro de material

18 Miguel Ángel Quesada Pacheco, Shán rójc brúncajc rójc: narraciones borucas (San José: Editorial Universidad de Costa Rica, 1996); y Espíritu Santo Maroto, Lengua o dialecto boruca o brúnkajk. Recopilación y presentación de Miguel Ángel Quesada Pacheco (San José: Editorial Universidad de Costa Rica, 1999) 135.

19 He podido sacar a la luz algunos de sus trabajos (Quesada Pacheco, 1996; y Maroto, 1999), pero desafortunadamente las inclemencias del tiempohicieron que se perdieran muchísimos trabajos, con lo cual el patrimonio boruca recopilado por Maroto se ha visto comprimido e incompleto. Aún quedan algunos papeles en manos de sus descendientes, con lo cual queda la esperanza de que muestren la necesaria generosidad para cederlos y darlos a publicación.

20 Miguel Ángel Quesada Pacheco, «Revitalización de las lenguas indígenas de Costa Rica: el caso del boruca», Anastasio Herranz (coord.), Marvin Barahona y Ramón Rivas, Educación bilingüe e intercultural en Centroamérica y México. Ponencias del Primer Simposio de Educación Bilingüe Intercultural en Honduras [Tegucigal pa, 27, 28 y 29 de julio de 1995]; (1998): 101-128.

En la actualidad funcionaria del Ministerio de Educación Pública. 
en lengua boruca que se haya conocido jamás, gracias a sus incansables visitas a las comunidades desde mediados de la década de 1980. Lejos de ser una escritura ideal ${ }^{22}$, la ausencia de divergencias dialectales en la lengua boruca ha favorecido la invención de un alfabeto práctico que ha ahorrado divergencias en la comunidad ${ }^{23}$. Quizás en el futuro le corresponda al boruca hacer las funciones de una lengua cultural, sobre la base de todos los materiales escritos y grabados de la actualidad, y de un supuesto interés por parte de los descendientes.

\section{La experiencia guaymí}

A diferencia de los borucas, los guaymíes siempre han sido demográficamente numerosos, desde la época colonial ${ }^{24}$. También, a diferencia de los primeros, el influjo de la Iglesia Católica no fue tan intenso durante la Colonia como entre los borucas ${ }^{25}$. A pesar de la presencia misionera de los franciscanos en pueblos fundados por ellos, como San Buenaventura de las Palmas y San Antonio de Guaymí, en la región de Veraguas, durante toda la Colonia recibieron calificativos como «ateos», «hostiles», «sediciosos» y «tumultarios», por su resistencia tenaz al dominio político y religioso español ${ }^{26}$. A principios del siglo $\mathrm{x} x$ hubo grupos protestantes interesados en impartir la fe cristiana, particularmente en los poblados de la costa atlántica, y en 1940 el

$22 \quad$ La escritura boruca sigue muy de cerca las irregularidades que presenta el español, como por ejemplo escribir diptongos iniciales con $<\mathrm{h}->$ y el fonema $/ \mathrm{k} /$ con $<\mathrm{c}$, qu $>$, en vez de haber aprovechado las grafias $\langle\mathrm{w}\rangle \mathrm{y}<\mathrm{k}\rangle$, como es el caso de otras lenguas del área (cabécar o bribri, para mencionar un par de idiomas).

23 Las divergencias que hay, fuera de ser muy pocas, parecen estar más bien relegadas al ámbito familiar, de modo que, por ejemplo, para los conceptos de 'padre', 'pan' y 'azúcar', unas familias prefieren decir yebéjt, cran utcá y babudij; otras, yuejt, shi?ua y up budón, respectivamente.

24 Reina Torres de Araúz, "Guaymíes (Movere)», Panamá indigena (1980) 215-268. Ciudad de Panamá: Instituto Nacional de Cultura, Patrimonio Histórico.

25 María Luisa Culebras Pérez y José Luis Iglesias Sequeiros, La Conquista: indigenas panameños, los Guaymies (San Vicente del Raspeig: Editorial Club Universitario, 2005); Fray Adrián de Ufeldre (1682). "Conquista de la provincia del guaymi», Tesoros verdaderos de las Indias, Fray Juan Meléndez (ed.) Vol. 3, Libro 1, Capítulo 1. Roma: N. A. Tunassio.

26 Solórzano (2002) 69, 72. 
misionero Ephraim Alphonse editó una gramática (<http:// countrystudies.us/panama/30.htm $>)^{27}$. Estos grupos se han preocupado por que los guaymíes continúen hablando su idioma, pese al inevitable proceso de deculturación aborigen que éstos representan con sus nuevas doctrinas.

En la actualidad, existe mucho interés por parte de los guaymíes en conservar su patrimonio lingüístico y cultural, y hay esfuerzos para la conservación del guaymí, entre los que se cuentan los realizados por el Ministerio de Educación Pública, la Universidad Nacional de Costa $\mathrm{Rica}^{28}$, el Instituto de Investigaciones Lingüísticas de la Universidad de Costa Rica ${ }^{29}$ y las instituciones gubernamentales de Panamá ${ }^{30}$, además de algunos grupos privados, particularmente grupos religiosos. No obstante, hay serios problemas por surcar y superar, entre los que se cuentan:

- La falta de coordinación entre las entidades educativas de los países participantes.

- Falta de coordinación entre las comunidades guaymíes a nivel nacional y extranacional.

- Ausencia de entendimiento entre los fines estatales y los intereses de las comunidades, lo cual crea conflictos que desfavorecían la investigación científica por parte de los no indígenas. Por ejemplo, en 1989, cuando el Estado costarricense otorgó cédula de residencia a los nuevos inmigrantes guaymíes provenientes de Panamá, el Ministerio de Salud tomó pruebas de sangre a 600

27 Paul L. Kirk, «Review of Guaymi Grammar and Dictionary, de Ephraim Alphonse», International Journal of American Linguistics 24 (1958): 84-85.

28 Ver <http://www.una.ac.cr/programas>.

$29 \mathrm{Ver}<\mathrm{http}: / / \mathrm{www}$.inil.ucr.ac.cr/proyecto.php?idProyecto=62>.

30 A diferencia de la Constitución Política de Costa Rica, que se refiere únicamente al español, la Constitución panameña declara en su artículo 84: «Las lenguas aborígenes serán objeto de especial estudio, conservación y divulgación y el Estado promoverá programas de alfabetización bilingüe en las comunidades indigenas".

31 COOPA/IETSAY, Narraciones Ngäbes: revitalización de la cultura tradicional (San José: Fundación Coordinadora de Pastoral Aborigen, 1997) 12. 
guaymíes, acto que fue visto y sentido como humillante entre los indígenas $^{31}$.

- La presencia de intereses encontrados entre instituciones estatales y privadas, algunas de las cuales quieren adjudicarse la dirección absoluta del patrimonio cultural guaymí, con lo cual a menudo se enf renta el investigador, en detrimento del objeto de estudio.

- Ausencia de consenso en materia de política lingüística, que redunda en la carencia de un alfabeto unificado en los libros de texto, con lo cual se pueden tener tantas maneras de escribir esta lengua como interesados en escribirla, y por consiguiente con incontables variantes. Parece que cada quien - los religiosos, los universitarios, los miembros de la comunidad, entre otrosquieren formar e imponer su propio abecedario, con consecuencias muy perjudiciales para el usuario.

- Falta de cohesión grupal, que lleve a la comunidad a tomar políticas conjuntas, olvidándose del parecer individual en materia de lengua ${ }^{32}$.

32 Durante mi última excursión a la comarca Ngäbe-Buglé, de Panamá, observé que los prinicpales de la comunidad de Salto Dupi rechazaron un libro de texto guaymi que había preparado el señor Quirós, maestro guyami de una población costarricense, porque no se ajustaba a lo que ellos consideraban escritura válida para su comunidad, y hasta afirmaron que Quirós no era guaymí.

33 Ver la bibliografia sobre los estudios del guaymí que ofrece el Instituto Lingüístico de Verano(<http:/ /www.ethnologue.org/show_serial.asp?name=491>). Por ejemplo: B. Arosemena y A. Melquíades, "La lingüística de texto aplicada a un texto narrativo guaymí», Estudios sobre el discursoen guaymi, Lenguas de Panamá 8 (Panamá: Instituto Lingüístico de Verano, 1980): 1-34; «Observaciones analíticas de un texto narrativo guaymi», Estudios sobre el discurso en guaymí, Lenguas de Panamá 8 (Panamá: Instituto Lingüístico de Verano, 1980): 35-59; y «Principales rasgos fonológicos del guaymí», Revista Latinoamericana de Estudios Etnolingüisticos 3 (1983): 87-119. Michael F. Kopesec, «Los elementos verbales y sustantivos y la oración en guaymi», Stephen $\mathrm{H}$. Levinsohn (ed.), Observaciones preliminares sobre los sistemas gramaticales de las lenguas chibchas, Lenguas de Panamá 2 (Panamá: Instituto Nacional de Cultura y Instituto Lingüístico de Verano, 1975): 1982; y Michael F. Kopesec y Bonnie M. Kopesec, «La jerarquía fonológica del guaymi», Priscilla M. Baptista (ed.), Sistemas fonológicos, Lenguas de Panamá 1 (Panamá: Instituto Nacional de Cultura y Instituto Lingüístico de Verano, 1974): 17-30. Stephen H. Levinsohn (ed.) Observaciones preliminares sobre los sistemas gramaticales de las lenguas chibchas. Lenguas de Panamá 2 (Panamá: Instituto Lingüístico de Verano, 1975). 


\section{Conclusión}

El guaymí se empieza a estudiar formalmente a partir de la segunda mitad del siglo $\mathrm{xx}^{33}$; sin embargo, pese a ser una lengua con tantos hablantes no ha sido estudiada profundamente. Quizás la dispersión de sus hablantes, los cuales viven en situación de extrema pobreza y en sitios de difícil acceso, haya contribuido a la falta de estudios sobre este idioma. Por otra parte, los guaymíes no conocían hasta hace algunos años políticas lingüísticas en su favor, las cuales han enfrentado con problemas diversos; ni estudiosos ni hablantes se ponen de acuerdo sobre el tipo de escritura por emplear para la alfabetización. Además, son dos países, Panamá y Costa Rica, los implicados en el asunto, y casi no hay contacto entre los propulsores de una y otra forma de educación. Cada país ha desarrollado políticas lingüísticas independientes, y la Constitución panameña distingue jurídicamente entre idioma y lengua, de acuerdo con la cual el primer concepto se refiere al español o a las lenguas extranjeras; el segundo, a las lenguas autóctonas ${ }^{34}$.

La situación boruca es abismalmente distinta, ya que los borucas han sido muy pocos y están asentados en un solo territorio, de acceso relativamente fácil. Además, el idioma boruca cuenta desde 1863 con estudios y descripciones. Los borucas han contado con educación lingüística en su lengua a partir de 1970, primero de forma particular a través de las lecciones voluntarias del señor Espíritu Santo Maroto; luego, en la década de 1990, con el apoyo formal y logístico del Ministerio de Educación Pública y de la Universidad de Costa Rica. El boruca no conoce las diferencias dialectales, por lo cual ha sido fácil la adaptación y aceptación de un alfabeto a partir del castellano. Hoy en día los habitantes tienen acceso gratuito a libros sobre leyendas, cuentos, diccionarios y textos didácticos.

$\overline{34}$ Ver los artículos 7, 78, 84, 86 y 96 de dicha Constitución. La Constitución de Costa Rica ni siquiera se refiere a las lenguas indigenas, solamente al español para referirse a él como al idioma oficial (artículo 76). 
No obstante, y a pesar de todos los esfuerzos, tanto por iniciativa privada de la comunidad como de las instituciones académicas y educativas, el boruca es el idioma en grave peligro de extinción. Varias son las causas, y los últimos hablantes monolingües en boruca datan de mediados del siglo xx. Por el contrario, los guaymíes han sido muchos desde por lo menos el siglo XVI, se extendían por grandes zonas de Panamá y desde esas épocas han mantenido su sólida cultura.

Lo presentado muestra dos situaciones lingüísticas dispares y prácticamente sin nada en común, lo cual lleva a plantear los siguientes objetivos que se deberán realizar en el corto plazo, tanto para el guaymí como para lo que queda de salvar del boruca:

1. Recopilar, entre los hablantes borucas, la mayor parte del material lingüístico y cultural posible, mediante intensas y frecuentes visitas a las localidades, con el fin de extraer de sus hablantes y habitantes la mayor parte de rasgos culturales posible. Todos los investigadores de la lengua boruca esperamos que en un futuro próximo se vean publicados los invaluables materiales recopilados por la investigadora Carmen Rojas.

2. En vista de que el guaymí cuenta con mayor número de hablantes, pero a la vez es una lengua escasamente estudiada, se podrán realizar encuestas lingüísticas entre los diferentes grupos nacionales (Panamá y Costa Rica), dialectales, generacionales y de ambos sexos, para sentar las bases de futuros estudios geolingüísticos, sociolingüísticos y pragmalingüísticos. Se podría aplicar cuestionarios, tanto lingüísticos como etnográficos, elaborados para la descripción general de una lengua y de los rasgos culturales principales.

3. Dar a conocer los materiales recopilados, sea mediante publicaciones o avances de investigación, en la población aborigen, con el fin de crear conciencia y de que vean concretizados sus propios esfuerzos, sin los cuales cualquier tarea para salvaguardar el patrimonio cultural sería vana. 
4. Formar equipos de trabajo interdisciplinario, específicamente con docentes, lingüistas, antropólogos, sociólogos y sicólogos, con el fin de trabajar juntamente con los pobladores de las comunidades indígenas, en tanto sujetos y principales beneficiados de los estudios que de este trabajo conjunto devengan ${ }^{35}$. Cualquier trabajo en otra dirección irá condenado al fracaso ${ }^{36}$.

5. Crear conciencia entre las instancias políticas de los países implicdos, y entre los grupos interesados (religiosos, educativos, informativos), sobre el esfuerzo de conservar el patrimonio cultural no se materializa con leyes, sino con acciones, a través del apoyo logístico y financiero para la realización de los trabajos interdisciplinarios y la publicación de los materiales que se recopilen.

6. Formar docentes que descarten la visión monolingüística y monocultural que ha dominado la tradición educativa elemental, en pro de un modelo pedagógico que tome en cuenta e incluya en el currículum el patrimonio lingüístico y cultural de las comunidades en cuestión ${ }^{37}$.

La tarea es inmensa, pero posible, como lo demostró el maestro boruca Espíritu Santo Maroto.

35 «Para una población como la guaymí es particularmente importante que un proyecto de desarrollo sea altamente participativo. Que la población pueda identificarse y comprometerse con el proyecto en vez de percibirlo como una propuesta ajena. Para ello es necesario crear oportunidades que permitan involucrar a la población desde el proceso de formulación del proyecto» <http:// www.ifad.org/evaluation/public_html/eksyst/doc/prj/region/pl/panama/rl36pmbs >.

36 Lo digo por experiencia propia, cuando en 1999 preparé un curso de lengua boruca para adultos, con el consiguiente fracaso, de no haber contado con la colaboración de otros expertos en materia de revitalización lingüistica. Miguel Ángel Quesada Pacheco, «Requiem por una lengua indígena costarricense: el caso del boruca», América Indigena 57, 3-4 (1997): 295-313.

37 López y Küper; Constanza Rojas-Primus, «Diversidad lingüística y alfabetización en América Latina y el Caribe», Revista Iberoamericana de Educación 40 (2006): 1-11. 